\title{
Textos de escravos no Brasil oitocentista: os tempos de uma edição filológica e de uma antologia comentada de alguns fatos linguísticos
}

Klebson Oliveira*

RESUMO: O evento que moveu e em torno do qual gravita o presente artigo foi a localização de 13 textos escritos por escravos no Brasil do século XIX. Tornam esses documentos raros o fato de os estudos históricos frequentemente apontarem para a afirmação de que esses indivíduos, por circunstâncias histórico-sociais, não tiveram acesso ao letramento. Tais documentos foram editados nos moldes de uma edição semidiplomática, tentando manter, o mais que se pudesse, as suas características originais. Feita a edição, o artigo deriva para um estudo linguístico em que estarão em causa, sobretudo, fenômenos ligados à aquisição da escrita, a fenômenos meramente gráficos e a fenômenos gráfico-fônicos.

PALAVRAS-CHAVE: Português brasileiro; textos de escravos; século XIX; análise linguística.

"Tudo neste mundo tem o seu tempo; cada coisa tem sua ocasião."

\section{Tempo de plantar}

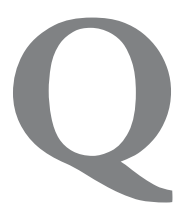

uando pesquisadores de várias partes do Brasil defloravam arquivos à procura de documentos para a construção de uma história do português brasileiro, veio Mattos e Silva com um texto, de 2002, denominado Para a história do português culto e popular brasileiro: sugestões para uma pauta de pesquisa, que se fez um norte para os que nesse

Universidade Federal da Bahia (PROHPOR)/Faculdades Jorge Amado/Unime klebsonoliveira1974@gmail.com. 
caminho se enveredavam. A proposta da autora já se insinua no título e o que desenvolverá será isto: as vias de reconstrução para o que teria sido o português culto e o português popular no passado brasileiro não podem ser idênticas, uma vez que o cenário, esse foi o mesmo, mas os atores eram diferentes.

Pois bem! Ainda consoante a autora acima referida, desvelar a face culta do português brasileiro em perspectiva diacrônica é tarefa bem alcançável, o que não quer dizer fácil, porque, além da generosidade dos arquivos, pode ser recuperada pela via tradicional, ou seja, pela busca de fontes documentais remanescentes, o que agenciaria, com o devir do tempo, a exibição de corpora diacrônicos seriados e constituídos pelos mais diversos tipos de textos. Isso, no ideário da autora, consentiria a aproximação de variações lingüísticas em convívio, bem como a detecção de mudanças ocorrentes. Já para uma história do português popular brasileiro, para esse, é bom avistar o modo como Mattos e Silva (2002, p. 457) lhe carimba o passaporte:

Tendo sido formado na oralidade o português geral brasileiro, antecedente histórico do português popular brasileiro, a busca do seu percurso histórico tem de ser feita não fundada em corpora escritos, organizáveis ad hoc, como para o português culto brasileiro, como é óbvio, mas num processo de reconstrução - que designarei metaforicamente •arqueológico, em que, de evidências dispersas, calçadas pelas teorias sobre o contato lingüístico e pela história social do Brasil, se possa chegar a formulações convincentes. Percurso análogo, mutatis mutandis e modus in rebus, ao da reconstrução do chamado 'latim vulgar', cuja principal fonte de estudo é o seu resultado, as línguas românicas.

É bastante palatável o pensamento da autora, uma vez que, segundo ela, era utente do português culto brasileiro uma minoria letrada, que deixou nos arquivos os seus rastros; é bastante palatável o pensamento da autora, uma vez que, segundo ela, eram utentes do português popular brasileiro os africanos e afro-descendentes, maioria iletrada da população. Mas Mattos e Silva (2002) vai mais longe: os que vieram de África e que aqui se multiplicaram não apenas difundiram, como também formataram e, conseqüentemente, concederam ao português americano as suas características típicas. Uma vez analfabetos, as pegadas desse português deverá ser rastreadas por outros caminhos, que não o dos arquivos, mas o do tipo arqueológico; essa é, pois, a sugestão da autora que, pensa-se, estima pela pertinência, dado o que dizem as pesquisas sobre a demografia histórica e sobre o itinerário do analfabetismo no Brasil de outras eras. Mas também do que diz Mattos e Silva (2002) fica um sabor, implícito que seja, de uma relação biunívoca entre africanos e afrodescendentes e o português popular brasileiro e a hipótese seguinte não deve ser deixada de lado: a de que muitos brancos, também esses, fizessem uso desse português. 
Quando se deriva o assunto para o lado dos escravos, a conjuntura, aquela a que se refere ao âmbito da leitura e da escrita, a princípio, mas só a princípio, "vai de mal a pior". Fausto (1994, p. 237), com base no primeiro censo oficial feito para o Brasil, em 1872, relata que, entre os escravos, o índice de analfabetos atingia 99.9\%. Imagine para antes! A historiadora Kátia Mattoso (2001[1982], p. 113) é dona de uma afirmativa célebre em que dá conta desse estado de coisas. Assim se manifesta:

\footnotetext{
A educação escolar do escravo é totalmente proibida no Brasil e os próprios forros não têm o direito de freqüentar aulas. Esta proibição será mantida durante toda a época da escravidão, mesmo durante a segunda metade do século XIX, em plena desagregação do sistema servil. Senhores e curas que resolvem ensinar a leitura e a escrita a escravos agridem as regras estabelecidas e são poucos. Eis porque o escravo brasileiro é um desconhecido, sem arquivos escritos.
}

Está aí um motivo que pode ter levado Serafim da Silva Neto, no seu Introdução ao estudo da língua portuguesa no Brasil, de 1950, a pressagiar o desconhecimento da fala de negros e escravos, dada a inexistência de documentação que espelhe o seu linguagar. Mas a porta aberta por Mattos e Silva (2002) vem dando, sim, o que contar. Ou seja, pelo que alcunhou de caminho arqueológico, justiça seja feita a Alkmim (2001, 2002), em que, através de evidências 'espalhadas' em fontes diversas - charges, informações de viajantes, anúncios de jornais etc. -, busca recuperar aspectos lingüísticos da fala de negros, sobretudo ao longo do século XIX. Leiam-se os trabalhos da autora nomeada e verifique-se o quanto é árduo e demorada a marcha que ela escolheu.

\section{Tempo de procurar}

Dizem que o diálogo é o mais profícuo dos meios para muitos empreendimentos. Defina-se este: desfazer a afirmação de Serafim da Silva Neto (1950) e a de Mattos e Silva (2002), pelo menos para o século XIX; o que quer dizer que a empresa apresentada aqui é encontrar escritos de escravos no Brasil oitocentista que possam, de algum modo, ofertar testemunhos sobre o seu linguagar e não deixar esse segmento da sociedade brasileira órfão quanto a algum conhecimento sobre o que fizeram da escrita em alguns de seus aspectos, lingǘsticos sobretudo.

Para a roda da conversa foram convocados antropólogos e, sobretudo, historiadores. E por falar em historiadores, Wissenbach (1998) presenteou a comunidade lingüística que se interessa pelos excluídos, quando descobriu, em arquivo de São Paulo, uma série de textos escritos pelo escravo Claro 
Antônio dos Santos, em seu nome e em nome de uma escrava analfabeta, Teodora. Mas que fique claro: não foi a única a dar o seu quinhão. Conversa vai, conversa vem, reuniram-se 13 textos saídos das mãos de escravos, que abraçam também alguns poucos fixados como a expressão da sua vontade. A própria Teodora fez isso, quando outros escreveram para ela, além do escravo Claro. Narrado o tempo do procurar, que venha o do ajuntar.

\section{Tempo de ajuntar}

Ajuntar 13 preciosos textos produzidos por escravos, é bom que se diga, já que, como foi dito acima, o panorama sobre o analfabetismo no Brasil fez com que muitos linguistas e historiadores apontassem para uma outra alameda: a improbabilidade de se descortinar um pouquinho do português vazado para o papel por essa fração, que foi bastante numerosa, da população do Brasil do século XIX. Daí que o adjetivo preciosos é mais que merecido. Ajuntar como? Em primeiro lugar, o público-alvo desses documentos são os linguistas, pelo que o acúmulo desses textos se fez através de uma edição semidiplomática com critérios - eles estão em anexo - que estimam pelo conservadorismo. Como decorrência disso e em segundo lugar, fez-se necessária a busca dos originais. Publicados ou não e para uma edição como a pretendida, a cata aos originais, estivessem eles onde estivessem, foi imperiosa. Em terceiro lugar, lá no final do artigo, estão meio que se abraçando os documentos, com um código, que será útil quando da composição de um item dedicado às suas características linguísticas; a mais: quem escreveu, onde escreveu e quando escreveu.

\section{Tempo de nascer}

Que esses textos, pelo viés da Linguística Histórica, estão sendo trabalhados pela primeira vez, isso não é verdade. Oliveira $(2004,2005$ a) ofertoulhes um estudo, emoldurando-os, sobretudo, quanto ao seu lugar social. Ou seja: procurou, primordialmente, saber quais as circunstâncias históricas que promoveram a escrita desses escravos, bem como outras questões; apenas um ponto importa dizer aqui: que esses indivíduos eram todos brasileiros. Mas esses exercícios de Oliveira, referidos já, embora voltando aos originais, embora oferecendo transcrições conservadoras, deu a conhecer, irregularmente, às vezes os documentos na íntegra e, mais frequentemente, fragmentos, pelo que é hora de um acerto de contas: apresentar todos os documentos, nos moldes de uma edição semidiplomática, na sua inteireza. 
Aqui e ali apresentou ainda o autor um retrato incompleto de algumas características linguísticas; fê-lo tão ligeiramente, porque o objetivo não era esse, que o presente artigo vem como que para 'reparar' esse hiato, por isso é hora de nascer um olhar mais verticalizado para o linguagar estabelecido nesses documentos. Um recorte, esse há de se assegurar e a prioridade vai para questões de aquisição da escrita, fenômenos gráficos e fenômenos fônicos. Outros, de leve, serão anunciados horizontalmente, porque os dados consentem o tempo de espalhar.

Por último, uma questão: deixa de ser este trabalho arqueológico, pelo fato de não está laborando com fontes indiretas, como fez Alkmim (2001, 2002)? Não, porque, embora seja os textos escritos pelas mãos dos próprios escravos, as evidências são dispersas, não no sentido que empregou Mattos e Silva (2002), mas por contar com poucos exemplares e deles se tirarão os novos tempos que estão por vir.

\section{Tempo de construir}

Leia-se a carta abaixo, uma das mais fonetizadas, e preste-se atenção ao que se negritou:

Illustríssimo Senhor J no cem so de Memto

\section{Sao Paulo $1^{\circ}$ de Ma ço de $18^{\prime \prime} 7$}

eu es tima e ri que eta dua linha que

05 V a a Cha o meu es ti ma do Senhor com muita Sau de como para mim dezeio noto bem para Vossa Mercê fil Ca Sa bem do que eu ia fai É es mom na que eu ando fora de mimha

10 caza eu ia Cuber que o Senhor vai para o Ju diahi vemho falla com Senhor Fr ancisco Be ne dito de Asil na Rua de Santa Curlze pe ga do o pos tao de minha caza falla com 
15 elle para mim Saber no mais

Sou de Vossa Mercê es i cravo criado $\mathbf{O}$

Birgado Claro Antonio $<$ do $>$ Santos

\author{
p2 \\ Illustríssimo Senhor I no cemCo \\ de mento e Sua \\ 20 fal zem da Vajes de Santo \\ Mar rio
}

Não só nesta, mas em todas as missivas, os escravos deram, por assim dizer, à escrita o que é da escrita. Repare-se na carta acima, por exemplo, e flagremse, para além de traços da fala que escorreram para o papel, fórmulas que são típicas de um texto escrito como o referido: saudação, local, data, fórmulas de iniciação do texto, agradecimento, menção do nome do autor, nome do destinatário e fórmula de endereçamento. Essa imagem exibe que os escravos, por mais elementares que fossem no manuseio da pena, intuíam e sabiam que a escrita tem ingredientes que são só seus.

E o que os dados têm a contar sobre fatos referentes à aquisição da escrita? O tópico que abrirá o panorama serão as hipo-segmentações - grafias de palavras que deveriam ser separadas, mas que foram grafadas juntas - e as hipersegmentações - a inserção de espaços em branco em palavras autônomas. Silva (1994), que trabalhou com corpus composto por redações de crianças em processo de aquisição da escrita, já contou que, por trás de resoluções gráficas em que a topografia do branco se afasta do cânone, estão soluções de como o aprendiz transmitem ao texto a percepção da fala como um contínuo fônico que se traduz na escrita, de modo que hipo-segmentações podem corresponder a grupos de força da linguagem oral; ${ }^{1}$ e a representação de palavra que se vai construindo em interação com o objeto escrito, porque algumas propostas para o espaço em branco põem em evidência a semelhança entre parcelas segmentadas e vocábulos autônomos, como o são os artigos, os pronomes, as preposições e as conjunções.

\footnotetext{
De Mattoso Câmara Jr. (2004a, p. 132) colhe-se o conceito de grupo de força, que consiste num sintagma de dois ou mais vocábulos, constituindo numa frase um conjunto fonético significativo, enunciado sem pausa intercorrente e subordinado a um acento tônico predominante, que é o do vocábulo mais importante do grupo. Há normalmente grupo de força (a) de um substantivo com seus adjuntos, (b) de um verbo com seu pronomesujeito, (c) de um verbo com seu complemento essencial etc.
} 
Dando toda razão a Marquilhas (2000, p. 244), que diz que o flagrante de hipo- e hipersementações envolve, em alguma medida, um quê de subjetividade, sobretudo quando se trata de escritos de outras épocas, o que os textos dos escravos expõem é algo bastante incomum em relação aos dados de autores que trabalharam com o tópico, principalmente em textos de crianças na atualidade e em relação também ao estudo de Oliveira (2005b), que se fixou em 290 documentos escritos por africanos e afro-descendentes na Bahia do século XIX: o acúmulo de hipo-segmentação se mostra bastante mais volumoso que os de hipersegmentação. Estaria os textos dos escravos indo, por assim dizer, "contra a maré"? Não se se espreitar que o promotor desse enviesamento foram os textos escritos pelo escravo Claro Antônio dos Santos, em seu nome e em nome da escrava Teodora, que compõem 7 dos 13 documentos em análise. Mas esse não é assunto a ser discutido com vagar. Que se faça, por conta disso, um exercício simples. Sem mais, apenas se aprecie a execução caligráfica do manuscrito abaixo, mas com um adendo: o "de virar as costas" para as suas características linguísticas, embora seja essa uma suscitação irresistível:

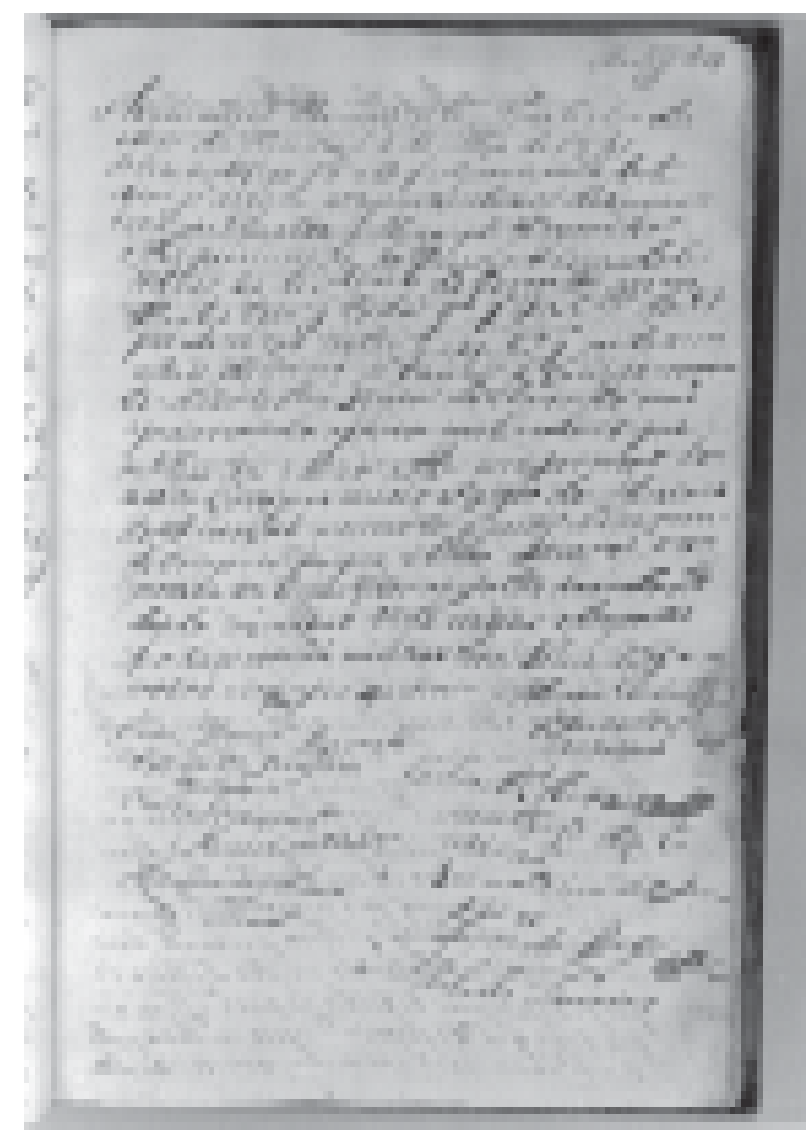


Está-se na Salvador de 1841 e sabe-se sobre o seu autor que se chamava Manoel da Conceição, veio de África, pertencia a uma irmandade negra e, é óbvio, tinha a faculdade das letras. Nada se manifesta sobre o seu maior ou menor domínio da escrita, a não ser pelas características lingüísticas, reveladoras de uma mão pouco habilidosa. Mas se pediu que deixasse de lado esse aspecto e se concentrasse apenas na execução caligráfica do autor. É aqui que entra um método fundado pelo paleógráfo italiano Antonio Petrucci, em um texto antológico de 1978, em que reconhece mãos elementares de base ou estacionadas em nível elementar de competência gráfica pelas seguintes características, como resumidas por Frascadore (1991, p. 118):

\footnotetext{
Gli scriventi in 'elementares di base' se caratterizzano per um tracciato molto transcurato, per l'incapacità di allineare perfettamente le lettere su um rigo ideale de scritura, per la tendenza a conferire loro um squadrato, per l'uso di um modulo grande, per l'impiego di lettere dell'alfabeto minúsculo anche all'interno di parola, per la quase totale assenza di abreviazioni e legamenti, per la rigidità e pesantezza dell'insieme sottoscrizione; tutte caratteristiche dovute ad um raporte molto salutario com la scrittura, usata evidentemente soltanto in maniera occasionale e discontinua.
}

Traçado descuidado, incapacidade de alinear com perfeição a escrita sobre uma linha, letras desenquadradas, módulos grandes, letras maiúsculas no interior de palavras e falta de leveza ao conjunto do texto, tudo isso que se vê na imagem acima mostra ser Manuel da Conceição uma mão estacionada em competência gráfica elementar, por isso, quando Oliveira (2006) prescrutinou documentos escritos por africanos e afro-descendentes na Salvador do século XIX, só encontrou dois textos de Manuel da Conceição, sinal de que fora convocado para escrever ocasional e descontinuamente. Avistese, agora, um escrito do Escravo Claro Antônio dos Santos e verifiquem-se as mesmas características elencadas por Frascadore, citada acima: 


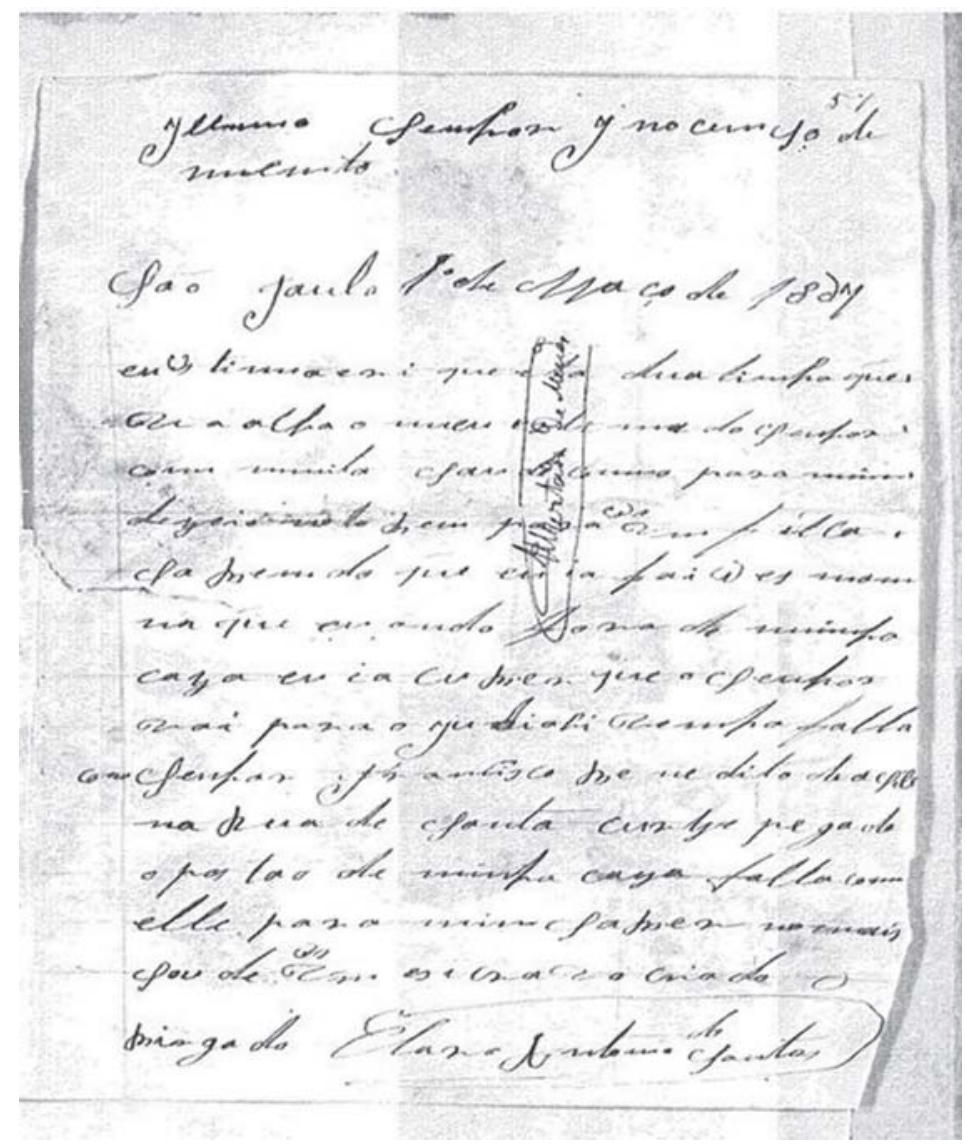

A escrita de Claro parece ter sido fruto de um uso difícil da pena, o que resultou em textos, ao que parece, penosos de serem feitos e, com frequência, teve ele de recorrer à soletração, por isso uma escrita extremamente silabada e repleta de hipo-segmentações. Disso vem aquele enviesamento que vai de encontro aos dados da escrita infantil e ao trabalho de Oliveira (2005b) sobre os negros do século XIX; o acúmulo de grafias em que o espaço em branco é introduzido imerecidamente mais que a escrita de palavras continuadas devese aos textos do escravo Claro. Acantonados esses, hipo-segmentações sobrepõem-se às hipersegmentações. E por falar no que no se falou, ou seja, no quesito execução caligráfica, os textos dos escravos podem ser divididos em dois grupos. De um lado, os textos de Claro, escritos em seu nome e também para a escrava Teodora, fixados como elementar de base; e de outro, os dos demais escravos, que, segundo Frascadore (1991, p. 118), podem se emoldu- 
rar no que designou de escrita usual, reconhecendo-lhes as seguintes características:

Le realizzazioni grafiche in 'usuale' presentano uma maggiore fluiditá, tracciato più regolare, modulo più piccolo delle lettere, bem serrate le une alle atre $\mathrm{e}$ meglio allineate, uso de abbreviazioni e di legimenti. É in generale la scrittura di chi há un'educazione grafica non rimasta relegata a liveli elementari, di chi la usa spesso per impegni lavorativi e professionali o, al contrario, di chi, pur avendo appreso um buon modello, lo ripete in maniera diligente senza avere però com esse una constante continuitá di esercizio. Questo gruppo, pertanto, si presenta più eterogeneo e variegato rispetto al precedente..

Vitorino, escravo que estava preso quando escreveu, é indivíduo, assim como os demais, com competência gráfica usual:

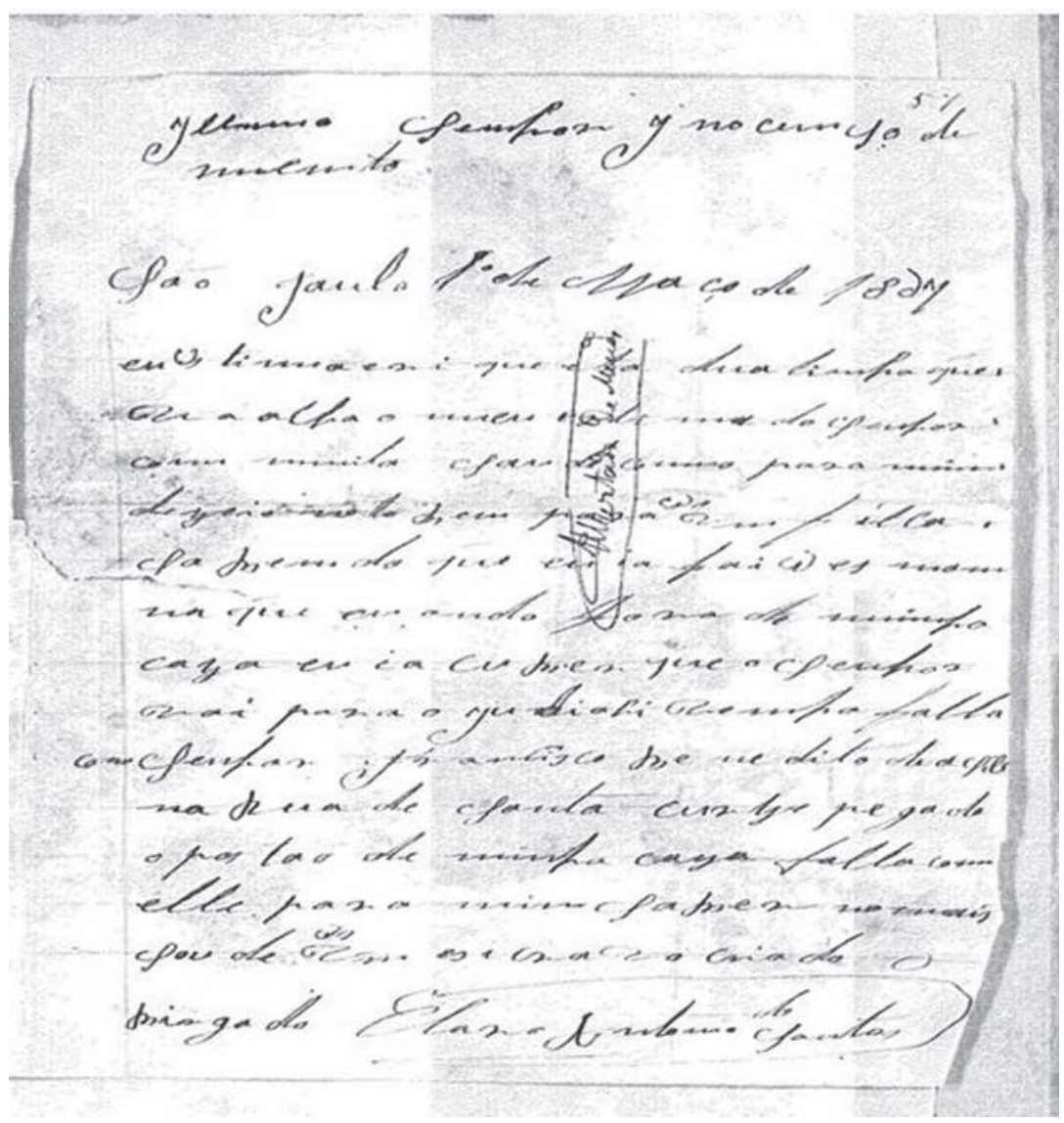


Esse desquite entre escravos em nível elementar e usual da escrita vai render, em outro artigo, comparações proveitosas, para se discutir uma hipótese que, implicitamente, Marquilhas (2000) semeou: a de que as marcas da oralidade se apresentam com mais constância no primeiro grupo.

Voltando às hipo-segmentações, primeiramente, vai-se encontrá-las nos seguintes exemplos: atodos (a todos, VIT, 1.04) ${ }^{2}$, aminha (a minha, VIT, 1.10), omeno (ao menos, VIT, 1.19), aproteição (a proteção, VIT, l.19), entoda (em toda, VIT, 1.32), Comtrabalho (com trabalho, VIT, 1.36), maiti a dora (mãe Teodora, TEO4, 1.11), mireis (mil réis, TEO3, 1.06), devortar (de voltar, TEO7, 1.04), cen (se eu, TEO7, 1.06), deu (de eu, TEO7, 1.09), servendia (ser vendida, TEO7, 1.09) meforca (me forçar, TEO7, 1.12), milreis (mil réis, TEO7, 1.15; TEO7, 1.15), ide (hei de, TEO2, 1.03), heidi (hei de,TEO2, 1.07), sepuder (se puder, TEO2, 1.10), vimfalar (vi falar, TEO2, 1.10), maranjar (me arranjar, TEO2, 1.14), dodefunto (do defunto,TEO2, 1.21), poriço (por isso, TEO1, 1.18; TEO1, 1.19; TEO1, 1.24), arainha (a rainha, TEO1, 1.20), ocasar (o casal, TEO1, 1.32).

Como bem constatou Abaurre (1991, p. 214) e Silva (1994, p. 87), para os dados das crianças, e Oliveira (2005b, p. 159), para os negros oitocentistas, também cá a ausência do branco é extremamente freqüente quando estão em causa artigos, conjunções, preposições e pronomes, palavras que podem funcionar como clíticas, sobretudo a um nome ou a um verbo, como o testemunham os seguintes exemplos: atodos, aminha, Comtrabalho, meforca etc.. Mas há umas espécies de hipo-segmentação que incluem duas palavras mais autônomas do ponto de vista prosódico: servendia, vimfala. Toda essa antologia parece mostrar que os escravos deixaram vir para a escrita a fala como ela é, ou seja, um contínuo fônico; vocábulos como ceu, deu, maranjar, em que não foram transcritas algumas letras e, conseqüentemente, não se estamparam as formas se eu, de eu, me arranjar, parecem querer não deixar dúvidas disso.

Para as hipersegmentações, apresenta-se um texto do escravo Claro, feito a mando da africana Teodora, para propor, como um vestígio a mais da sua pouca competência no manuseio da pena, que o fenômeno resulta de uma escrita silabada, antecedida, ao que parece, por inúmeras soletrações, em que a sílaba é a unidade mais óbvia:

2 Indicam-se, entre parênteses, a grafia canônica, a abreviatura do texto editado, que se encontra no final do artigo. Para a localização da ocorrência dos fenômenos que serão mencionados nos documentos, segue o número da linha. 
Illustríssimo Senhor i nos senÇo

e m São Paulo 20 de < novembor [?] $>$

05 Meo filho eu es de ti ma muito e a sua sau de conno para mim dezeio noto bem pa vo es mi mandra comta como vai de sau de nos mais eu bos to a mimha bremcao Deos te a be so para muito tempo ti de sau

10 de como para nim deze no to bem para sou a tua maiti a dora no mais a Deos $\mathrm{p} 2$ Illustrímo Senhor no cemso

15 hum a falzemda de par to [?] Luize Bira $<$ po $>$ ra Ju di a hi

Avistem-se algumas outras hipersegmentações, colhidas dos textos, atentando-se, mais essa vez, para as parcelas dos vocábulos em negrito: a mor (amor, TIM, 1.12), a qui (aqui, TEO7, 1.06), com migo (comigo, TEO2, 1.10-11; VIT, 1.22; TEO3, 1.05), a char (achar, TEO1, 1.02; VIT, 1.03), a visou (avisou, TEO1, 1.14), em tão (então, TEO1, 1.34), a conteceu (aconteceu, VIT, 1.27), sau de (saúde, TEO4, 1.06), no cemso (Inocêncio, TEO4, l.14), hum a (uma, TEO4, 1.15), es da (seda, CLA1, 1.04; CLA1, 1.07), mari do (marido, TEO5, 1.01), mam da (mandar, TEO6, 1.08). O exemplário parece apontar para o fato de que, dessa vez, a inserção imerecida do espaço em branco em uma palavra nada tem a ver com soletração, mas sim com um conhecimento que se apropriou da própria escrita; basta observar que uma das parcelas isoladas pelo branco no vocábulo se identifica com outras que gozam de estatuto autônomo, como os artigos, as preposições etc. As mãos identificam, desse modo, não uma, mais duas palavras; prova disso são as seguintes: a Sis (Assis, CLA2, 1.06), a Deos (adeus, TEO4, 1.11), a Cha (achar, CLA3, 1.05; TEO6, 1.04), em que a segunda porção isolada pelo branco inicia-se com letra maiúscula e se diferencia das suas correspondentes minúsculas pelo tamanho e pela morfologia. Pelo que fazem perceber os textos, o uso de letras capitais tem muito mais ocorrências no princípio de palavras. 


\section{Tempo de arrancar}

Cava-se de estudos sobre sincronias presentes e passadas que a irregularidade ortográfica na escrita de sílabas complexas com os segmentos líquidos, sobretudo o $/ \mathrm{r} /{ }^{3}$, é traço sem época, sem lugar e sem idade. Aconteceu com as mãos inábeis portuguesas do século XVII estudadas por Marquilhas (2000, p. 246) (afrimar por afirmar, faz̧e por fazer, cabars por cabras, cirstão por cristão); aconteceu com as crianças francesas dos séculos XIX e XX (devert por devret $=$ devraient $)$ analisadas por Blanche-Benveniste (1998, p. 138); aconteceu com os negros oitocentistas examinados por Oliveira (2006) (Ander por André, enter por entre, palavar por palavra); aconteceu com crianças brasileiras da atualidade consideradas por Abaurre (2001, p. 63-85) e Zorzi (1998, p. 80-82) (magar por magra, pober por pobre, quato por quarto, entoru por entrou); aconteceu com adultos brasileiros em fase inicial de aquisição do código escrito pesquisados por Kleiman (2001, p. 232) (aleguer por alegre) e por Picoli (2001, p.115) (pobemas por problemas). Aconteceu também com os escravos cujos textos estão em análise.

São 32 dados a exibirem a irregularidade ortográfica da escrita de uma sílaba complexa, quando está em causa o /r/. Neste primeiro grupo, com 14 ocorrências, o expediente utilizado foi deslocar o grafema para outro local dentro da sílaba: novembor (novembro, TEO4, 1.2), mandra (mandar, TEO, 1.7), pader (padre, TEO3, 1.10), garça (graşa, TEO3, 1.12), pormeça (promessa, TEO1, 1.09; TEO1, 1.10; TEO1, 1.13-14; TEO1, 1.16; TEO1, 1.35), por meça (promessa, TEO7, 1.7), persa (presa, TEO1, 1.18; TEO1, 1.21), Curlze (Cruz CLA3, 1.13), O Birgado (obrigado, CLA3, l.17). Já nas ocorrências seguintes, 18 no total, o que se assiste é a omissão do grafema que traduziria a vibrante: $i$ tegue (entregue, TEO3, 1.16), peta (preta, CLA1, 1.03; CLA1, 1.08), pe ta (preta, CLA1, 1.07), ga vata (gravata, CLA1, 1.03), bamCo (branco, CLA1, 1.06), bin Co (brim, CLA1, 1.09), com es va (conserva, CLA1, 1.14), pecura caõ (procuração, CLA1, 1.17), pe da (pedra, CLA1, 1.14), compir (cumprir, TEO1, 1.17; TEO1, 1.26), desfacado (disfarçado, TEO1, 1.28), propio (próprio, TEO2, 1.15), Ma ço (março, CLA3, 1.03), Je tu de (Gertrudes, CLA2, 1.02), mizeicode (misericórdia, TEO3, 1.12). Adverte-se: em primeiro lugar, a irregularidade ortográfica optou, mesmo com pouca diferença em relação ao total dos itens, pela não transcrição da vibrante; em segundo lugar, que as estruturas com o /r/ em ataque ramifica-

3 Por questões de economia na descrição, utilizar-se-á, assim como fizeram Marquilhas (2000, p. 245-257) e Barbosa (1999, p. 159-163), o /r/ para se referir à vibrante em todas as posições silábicas em que pode ocorrer. Do mesmo modo, empregar-se-ão o /1/ para a lateral e o /s/ para a sibilante. 
do alojam, com saldos bem volumosos, mais o fenômeno do que na posição de coda, pelo que se aposta que, com as estratégias utilizadas, os padrões silábicos $\mathrm{CV} / \mathrm{r}$ / e CV se apresentassem como mais naturais que $\mathrm{C} / \mathrm{r} / \mathrm{V}$.

Para o /1/, detectam-se apenas 4 ocorrências: ma vado (malvado, TEO3, 1.10), Bucão (Bulcão, VIT, 1.01), cumpado (culpado, TEO7, 1.9), a gu m (algum, TEO5, 1.5), sem a exibição de nenhum deslocamento, só omissões. Está aqui a prova, já mostrada por Marquilhas (2000, p. 257), para os inábeis portugueses dos seiscentos, e por Oliveira (2006, p. 282), para os africanos e afrodescendentes brasileiros do século XIX, de que, também na representação fonológica dos escravos, a lateral é um segmento mais estabilizado que a vibrante. Mas Oliveira, no trabalho acima referido, ainda expõe que não apenas os segmentos líquidos conduzem à irregularidade ortográfica, como também a sibilante /s/ e isso volta a aparecer nos textos dos escravos em 12 casos, em que a alternativa foi não transcrever o segmento. Veja-se a antologia: e ta (esta, TEO3, 1.3; CLA1, 1.17; CLA3, 1.04; TEO6, 1.4; TEO6, 1.8), repota (resposta, TEO3, 1.7), i tou (estou, TEO3, 1.9), i crava (escrava, TEO3, 1.10), i cravo (escravo, TEO3, 1.17), i to jo (estojo, CLA1, 1.15), reposta (resposta, TEO2, 1.12), reponsado (responsável, TEO7, 1.11).

Para um comentário final, avisa-se que, embora considerando o tópico como referente a dificuldades na aquisição da escrita de sílabas complexas, nada impede que os inúmeros dados também sejam interpretados como que depondo metáteses e síncopes ocorrentes na linguagem oral e que, por sua vez, se estampam na escrita.

Quanto ao grupo de fenômenos que serão apresentados agora, BlancheBenveniste (1998, p. 163-176) insiste em denominá-lo de "erros mecânicos", porque, segundo ela, não comprometem o entendimento do texto. Oliveira (2006, p. 296) questiona-lhe o rótulo e prefere chamá-lo de fenômenos gráficos. $\mathrm{Na}$ verdade, sob essa embalagem encontram-se acréscimos, omissões, inversões e substituições de grafemas, palavras e até de frases inteiras. Será sobre os grafemas que se deterá. Quanto ao acréscimo, tem-se o exemplário com 20 ocorrências: bos to (boto, TEO4, 1.7), bremcao (benção, TEO4, 1.7), falzemda (fazenda, TEO4, 1.15), gorzando (gozando, TEO3, 1.3), fer verio (fevereiro, CLA1, 1.01), cor lete (colete, CLA1, 1.03), car be ça (cabeça, CLA1, 1.05), bin Co (brim, CLA1, 1.09), Imal (mal, TEO1, 1.18), façilital (facilitar, TEO1, 1.1819), carsar (casal, TEO1, 1.29), compraei (cumprirei, TEO7, 1.6), fil Ca (ficar, CLA3, 1.07), fil ca (ficar, CLA2, 1.04), Curlze (Cruz, CLA3, 1.13), fal zem da (fazenda, CLA3, 1.20), solrcrava (Sorocaba, TEO3, 1.8-9), solrcrava (Sorocaba, TEO3, 1.8-9), es (hei, TEO3, 1.3; TEO4, 1.5). 
O que se vê é a colocação de uma sílaba, bin Co (brim, CLA1, 1.09), de uma vogal, Imal (mal, TEO1, 1.18) e compraei (cumprirei, TEO7, 1.6), mas, principalmente e mais sistematicamente, dos grafemas $<\mathrm{r}>,<\mathrm{s}>$ e $<\mathrm{l}>$. Observe-se que a eleição dos grafemas nomeados não parece aleatória, porque as mãos, talvez num mal palpite de como se escreveria essas palavras, optou por essas letras no lugar certo, só que no vocábulo errado. É como se ocupassem a posição de coda ou de ataque ramificado, lugares que, de fato, lhes cabem, formando o que se poderia denominar de falsas sílabas complexas. Duas formas chamam a atenção. Em Curlze (Cruz, CLA3, 1.13), o problema, de fato, parece ter a ver com a aquisição da escrita; a mão, sem saber ortografar o padrão $\mathrm{C} / \mathrm{r} / \mathrm{C}$, deslocou o grafema e, mesmo assim, não ficou satisfeita com a colocação do $<\mathrm{r}>$. Pode ser uma outra letra, $\mathrm{o}<\mathrm{l}>$, deve ter pensado; na dúvida, as duas. Já em façilital (facilitar, TEO1, l.18-19), o apagamento do /r/ final pode estar em causa, mas o promotor da grafia referida pareceu ressentir-se de que a última sílaba carecia de uma letra a mais, daí convocou o $<1>$. Mas uma vez, é o grafema no lugar certo, mas a palavra é que não é.

Exemplos de grafias, 13, que manifestam a omissão de grafemas, vocálicos e consonânticos, e de sílabas: deze (dezejo, TEO4, 1.10), otu... (outubro, TEO3, 1.3), o tu (outubro, TEO6, 1.3), fer verio (fevereiro, CLA1, 1.01), s (se, ARN, 1.17), czo (caso, TEO2, 1.13), compraei (cumprirei, TEO7, 1.6), vidia (vendida, TEO7, 1.9), com (como, TEO6, 1.6), Jeus (Jesus, CLA2, 1.03), di (dita, CLA2, 1.08), solrcrava (Sorocaba, TEO3, 1.8-9), mizeicode (misericórdia, TEO3, 1.12). Presume-se, por causa da coletânea oferecida, que a omissão está bem ligada a vocábulos de cumprimento extensos e que, como um acessório a mais, oferecem em sua estrutura padrões silábicos complexos. De uma mão, veio um expediente bem esperto: talvez por não ter a certeza de como grafar a última sílaba de um vocábulo, valeu-se das bem-vindas reticências - otu... (outubro, TEO3, 1.3). Esse caso, s (se, ARN, 1.17), também merece uma nota, porque a não inscrição do grafema $e$ pode estar relacionado ao que Cagliari (1998, p. 124) chamou de princípio acrofônico, ou seja, o som da letra identifica-se com o som da sílaba.

Elas, perfazendo sete casos, também deram o "ar da graça" nos textos dos escravos: as inversões na ordem dos grafemas. Ei-las: qeu (que, TEO3, 1.3), es da (seda, CLA1, 1.03; CLA1, 1.04; CLA1, 1.07), com es va (conserva, CLA1, 1.14), es tima e ri (estimarei, CLA3, 1.04), es momna (semana, CLA3, 1.0910). Importa relevar que todas as inversões é obra de uma mesma mão e a dificuldade se concentra, sobretudo, em assentar, em escrita cursiva, a sílaba se, estampada como es. Seria por que o primeiro grafema é mais fácil de desenhar do que o segundo? Se assim o é, por que o autor não imprimiu a inversão 
para outras sílabas além dessa? Como se vê, há de se esperar pelo tempo de respostas.

Servirá também para outros, mas, sobre esse último fenômeno a ser apreciado, sob o rótulo de gráficos - as substituições de grafemas -, cabe antes um aparte sobre a questão da nasalidade e, para isso, as palavras de Simões (2003, p.64) sobre o tópico entre os alfabetizandos:

\begin{abstract}
Considerando que a nasalidade é uma situação de maior complexidade, concluímos que, no plano fônico, ela não atordoa o alfabetizando, pois, captando-a ou não, a criança resolve sua grafia de forma sistêmica e estruturada: ou ignora e, portanto, não usa marcas, ou a percebe e elege uma marcação uniforme: põe travador (consoante nasal após a vogal fechando sílaba) ou til em todas as sílabas que apresentem qualquer vestígio de som nasal (nasaladas e nasalizadas).
\end{abstract}

Desse modo, que não se veja nas grafias seguintes encenação de desnasalizações. Os escravos, assim como os alfabetizandos, podem, simplesmente, ter optado pelo desuso de marcas para representar a nasalidade: Agola (Angola, TEO7, 1.10), lem braça (lembrança, TEO2, 1.08), vidia (vendida, TEO7, 1.9), querede (querendo, TEO7, 1.12), defuto (defunto, TEO2, 1.21), vedeu (vendeu, TEO1, 1.12), braços (brancos, TEO1, 1.27), mai (mãe, ARN, 1.13; ARN, 1.17; TEO4, 1.11), a mor ri (amorim, CLA1, 1.12).

Ainda Simões (2003, p. 64) sobre o assunto:

\begin{abstract}
É possível a verificação de fenômenos como canna (= cana), bananna (=banana), lanma (=lama). Nestes casos, a criança percebe a nasalização fonética regressiva pela contaminação com o aclive consonantal nasal da sílaba posterior e marca graficamente essa diferença.
\end{abstract}

Dessa maneira, que não se guardem também na antologia seguinte manifestações de grafias etimologizantes. É, tão-somente, a imagem do que desenhou a autora acima dita: es momna (semana, CLA3, 1.09-10), de mi cian no (Domiciano, TEO6, 1.1, TEO3, 1.8), lin nera (Limeira, TEO6, 1.9; TEO3, 1.19), vom (vão, TEO3, 1.3), conno (como, TEO4, 1.6). Para o vocábulo muito, ainda segundo Simões (2003, p. 64), há quem a registre com til ou travador, indicando graficamente a nasalização fonética prospectiva (a consoante nasal contamina o som vocálico conseqüente). Nesse particular, merece relevo o expediente encontrado por um escravo para assinalar a nasalização referida no vocábulo também referido: Mumito (muito, TEO2, 1.03; TEO5, 1.3).

Volte-se, pois, para as substituições de grafemas e veja-se como se exibem em 8 casos: Be me di to (Benedito, CLA1, 1.18), Jaia (Iaiá, TIM, 1.06), pos tao (portão, CLA3, 
1.14), lin nera (Limeira, TEO6, 1.9), conno (como, TEO4, 1.6), nim (mim, TEO4, 1.10). Com exceção de Asil (Assis, CLA3, 1.12) e a Sil (Assis, CLA1, 1.18) e observando-se os escritos dos escravos bem de perto, para todas as demais ocorrências a explicação é única: as substituições de grafemas são promovidas pela morfologia próxima das letras.

\section{Tempo de construir}

De construir os fenômenos fônicos ocorrentes na fala e que deixaram as suas pegadas nos textos dos escravos. As aféreses, por exemplo, em que se subtraem fonemas no início de um vocábulo, comparecem em 10 ocorrências: hinda (ainda, TEO1, 1.25-26), forria (alforria, TEO1, 1.28), Memto (Nascimento, CLA3, 1.02), mento (Nascimento, CLA3, 1.19), Mar rio (Amaro, CLA3, 1.21), ti ma (estimar, TEO6, 1.4; TEO4, 1.5), tima (estimar, TEO3, 1.3), no cemso (Inocêncio, TEO4, 1.12), tou (estou, TEO5, 1.7). Vendo como se pode, ela, a aférese, acerta sílabas de variadas estruturas. Já o seu reverso, a prótese, ou seja, o acréscimo de fonemas no início do vocábulo, é convocada em 1 ocorrência solitária, que é um verbo: a re ce ber (receber, CLA2, 1.08).

As síncopes, subtração de fonemas no interior de palavras, também elas dão, em 3 casos, os seus ares: São Bendicto (São Benedito, TEO1, 1.22-23), connio (cônego, TEO2, 1.17), comgo (cônego, TEO5, 1.8). Note-se que as 2 ocorrências finais têm a ver com redução de palavras proparoxítonas. E quanto às epênteses, o oposto da síncope, guardadas estão no seguinte exemplário: dispois (depois, TEO1, 1.33), dispos (depois, TEO1, 1.36), addemirava (admirava, TIM, 1.12), es i cravo (escravo, CLA3, 1.16), esi Cravo (escravo, CLA2, 1.10). Ressalta-se que o encravamento do /s/ nos 2 primeiros casos já teve a sua vitalidade no português arcaico, porém, do ponto de vista do português atual e do século XIX, pode-se, sim, falar em epêntese, na medida em que, muito cedo, cede espaço para que a variante depois se generalize. Lembra-se que o terceiro caso vem como que para desfazer o que se designou chamar de grupos consonânticos eruditos. Por fim, adverte-se que as 2 últimas ocorrências cobiçam tornar CV uma estrutura silábica que não o é.

Navega-se para o final da palavra, mais especificamente para noticiar sobre as apócopes, aquele fenômeno caracterizado pela subtração de fonemas. Os dados licenciam a constituição de 3 grupos e se falará, primeiramente, da apócope do /r/. São 24 ocorrências a exibi-las, sendo que dessas 22 recaem sobre verbos no infinitivo. Vão-se alguns exemplos contextualizados: 
...eu vos is Crevo para Vossa Mercê selembra daquela promeça que nois fizemos eu heidi pricura por vose (TEO2, 1.05-07)

mi fazer o fa vou de vi por o nata falla com migo sem falta (TEO3, 1.05-06)

Meo filho eu es de ti ma muito e a sua sau de conno para mim dezeio... (TEO4, 1.05-06)

...mi faça o favor de mi ajum ta a gu $\mathrm{m}$ dimhe ro para mim eu já tem ho É4 mireis (TEO5, 1.04-06)

no to bem para Vossa Senhoria mi faca o fa vo $<\mathrm{r}>$ de mi mam da eta crata para... (TEO6, 1.06-08)

Cen eu isto querede meforca quero Vossa Mercê de lisensa para eu tira esmola nos domingo para hi dando para Sinhor (TEO7, 1.11-14)

noto bem para Vossa mercê fil ca Saben do que eu paso a min $<$ há $>$ or dem para Senhor meu ami go Francisco Be ne dito de a Sis a quantia de Sem mi reis (CLA2, 1.03-06)

eu es tima e ri que eta dua linha que $\mathrm{V}$ a a Cha o meu es ti ma do Senhor com muita Sau de como para mim (CLA3, 1.0406)

eu ia Cuber que o Senhor vai para o Ju diahi vemho falla com Senhor Fr ancisco Be ne dito de Asil na Rua de Santa Curlze pe ga do o pos tao de minha caza... (CLA3, 1.11-14)

Tem-se mulhe por mulher (TEO3, 1.13) e favou por favor (TEO3, 1.5): essas são as 2 únicas ocorrências de apócopes que não dizem respeito a verbos, com o detalhe de que, nessa última, o apagamento do /r/ final favoreceu uma ditongação. Sobre os 2 grupos finais há a pronunciar que computam alguns exemplares da apócope de $/ 1 /, 5$, e de /s/, 7, tal como se mira na listagem seguinte: nata (natal, TEO3, 1.5), mireis (mil reis, TEO3, 1.6; TEO5, 1.6), mi reis (mil réis, CLA2, 1.06), omeno (ao menos, VIT, 1.19), dua (duas, CLA3, 
1.04), fai (far, CLA3, 1.08), Je tu de (Gertrudes, CLA2, 1.02), no (nos, TEO3, 1.12). Aproveita-se logo para colocar as duas ocorrências de acréscimos de fonemas em final de vocábulos, ou seja, as paragoges: Curlze (Cruz, CLA3, 1.13), Luize (Luis, TEO4, 1.17).

Reduziram-se, nos textos, 22 ditongos: [yu] > [u]: i nos senÇo (Inocêncio, TEO4, 1.1), I no cemCo (Inocêncio, CLA3, l.18), J no cem so (Inocêncio, CLA3, 1.01), no cemso (Inocêncio, TEO4, 1.12), Si to (sítio, CLA2, 1.12); [ey] > [e]: dinhero (dinheiro, TEO2, 1.09; TEO2, 1.12), Limera (Limeira, TEO2, 1.22), lin nera ( $L i$ meira, TEO6, 1.9; TEO3, 1.19); [ow] > [o]: Cazoci (casou-se, VIT, 1.23), otu... (outubro, TEO3, 1.3), o tu (outubro, TEO6 1.3); [ey] > [i]: i (hei, TEO2, 1.03; TEO6, 1.4), es (hei, TEO3, 1.3; TEO4, 1.5); [aw] > [o]: omeno (ao menos, VIT, 1.19), omento (aumento, VIT, 1.32); [ya] > [i]: mizeicode (misericórdia, TEO3, 1.12); [u)y)] > [u]]: Muto (muito, TEO1, 1.02); [ãw)] > [õ]: vom (vão, TEO3, 1.3).

Por outro lado, a ditongação comparece em 12 casos; em sua maioria com a inserção de [y] e em apenas 1 com o acréscimo de [w]: voes (vós, TEO4, 1.7), proteição (proteção, VIT, 1.19), esteije (esteja, TEO1, 1.03), dezeijo (desejo, TEO1, 1.04), veija (veja, TEO1, 1.20), nois (nós, TEO2, 1.06), Theodoria (Teodora, TEO2, 1.17), Ti o do ria (Teodora, TEO7, 1.18), infaime (infame, TIM, 1.18; TIM, 1.26), fai (far, CLA3, 1.08), Mar rio (Amaro, CLA3, 1.21), favou (favor, TEO3, 1.5).

$\mathrm{O}$ alteamento de vogais pré-tônicas se fazem presentes em 32 ocorrências, sendo que, desses índices, apenas 4 dizem respeito às medias posteriores: filicidade (felicidade, TEO3, 1.4), fili cida de (felicidade, TEO6, 1.5), i tegue (entregue, TEO3, 1.16), i tou (estou, TEO3, 1.9), is tou (estou, TEO2, 1.04), i crava (escrava, TEO3, 1.10), $\mathbf{i}$ cravo (escravo, TEO3, 1.17), is Cravo (escravo, TEO2, 1.20), Is Crava (escrava, TEO7, 1.17), $\mathbf{i}$ to jo (estojo, CLA1, 1.15), obidiente (obediente, VIT, 1.05), Ingenho (Engenho, VIT, 1.25), attindido (atendido, VIT, 1.31), dispois (depois, TEO1, 1.33), dispos (depois, TEO1, 1.36), istimar (estimar, TEO2, 1.03), isteja (esteja, TEO2, 1.03-04), is Crevo (escrevo, TEO2, 1.05), vin dida (vendida, TEO2, l.18), disgostos (desgostos, TIM, 1.05), promiti (prometi, TEO7, 1.4), vidia (vendida, TEO7, 1.9), Sinhor (Senhor, TEO7, 1.11; TEO7, 1.14), Ti o do ria (Teodora, TEO7, 1.18), Ti a do ra(Teodora, TEO6, 1.11; TEO3, 1.14), ti a dora (Teodora, TEO4, 1.11), pur tanto (portanto, VIT, 1.21), pur que (porque, VIT, 1.23), urige (origem, VIT, 1.27), arfuria (alforria, TEO1, 1.32). Já o mesmo fenômeno, só que em monossílabos, se estampam em 18 casos: mi (me, TEO5, 1.4; TEO5, 1.5; TEO6, 1.7; TEO6, 1.8; TEO4, 1.7; TEO3, 1.5; TEO3, 1.7; TEO3, 1.6; CLA2, 1.09), ti (te, TEO4, 1.9), i (e, CLA1, 1.08; CLA1, 1.09), di (de, TEO2, 1.07), pur (por, CLA2, 1.07), Mai (mãe, VIT, 1.12), mai (mãe, TEO4, 1.11; ARN, 1.13; ARN, 1.17). 
Já o abaixamento de vogais altas se exibem em 10 ocorrências: devima (divina, TEO3, 1.12), enfeliz (infeliz, VIT, 1.02), comprir (cumprir, VIT, 1.10), compir (cumprir, TEO1, 1.17; TEO1, 1.26), comprice (cumprice, TEO7, 1.3), compraei (cumprirei, TEO7, 1.6), deferencia (diferença, VIT, 1.26), enfelicidade (infelicidade, VIT, 1.28), desfacado (disfarcado, TEO1, 1.28). Ainda quanto a fenômenos relacionados a vogais, assistimos a: 4 centralizações - te $\mathbf{a}$ do ra (Teodora, TEO5, 1.10), Ti a do ra (Teodora, TEO6, 1.11; TEO3, 1.14), ti a dora (Teodora, TEO4, 1.11); 5 anteriorizações - pecura caõ (procuração, CLA1, 1.17), pricura (procurar, TEO2, 1.07), querede (querendo, TEO7, 1.12), de mi cian no (Domiciano, TEO6, 1.1; TEO3, 1.8) e 1 posteriorização - Cuber (saber, CLA3, 1.10).

Rotacismos, todos em posição de coda, são 8 casos os testemunhando: arfuria (alforria, TEO1, 1.32), car ça (calça, CLA1, 1.08; CLA1, 1.09), carsar (casal, TEO1, 1.29; TEO1, 1.30; TEO1, 1.32), Carçado (calçado, VIT, 1.20); vortar (voltar, TEO7, 1.4). Quanto ao ieismo, vão-se as 7 ocorrências a seu respeito: vermeia (vermelha, CLA1, 1.11), na vaia (navalha, CLA1, 1.15), dezeio (desejo, CLA3, 1.07; TEO3, 1.4; TEO4, 1.6; TEO5, 1.4; TEO6, 1.6). Como derivam de consoantes palatais, esse fenômeno pode receber outro nome: despalatalização.

Para ultimar o tópico, ou seja, marcas fônicas na escrita, acrescentamse 3 nasalizacões - a jun de (ajude, TEO3, 1.12), enxú (exú, TEO7, 1.7), cumpado (culpado, TEO7, 1.9) - e 2 desnasalizações - urige (origem, VIT, 1.27), Varjes (Vargens, CLA3, 1.20).

\section{Tempo de espalhar}

Colocam-se aqui, a pretexto também de finalizar o artigo, algumas particularidades lingüísticas, encontradas nos textos, que vão além de problemas de aquisição da escrita e de fenômenos gráficos e fônicos.

- Concordância nominal: 4 ca miza de a mor ri fim mo (CLA1, 1.12), 2 ca mi za de xita (CLA1, 1.13), Claro Amtonio do Santos (CLA1, 1.19), Claro Antonio <do> Santos (CLA3, 1.17), eta dua linha (CLA3, 1.04), É es momna (CLA3, 1.08), da Vajes (CLA3, 1.20), estas enfeliz Linhas (VIT, 1.02), destas enfeliz linhas (VIT, 1.06-07), Vossos honrado pés (VIT, 1.07-08), aproteição dos Carçado de minha Senhor Maria (VIT, 1.19-20), nos domingo (TEO7, 1.14).

- Concordância de gênero: a minha Senhor Maria (VIT, 1.09; VIT, 1.20; VIT, 1.2324).

- Concordância verbal: eu es tima e ri que eta dua linha que $\mathbf{V}$ a a Cha o meu es ti ma do Senhor com muita Sau de... (CLA3, 1.04-06), mi falta 198 mireis para minha li ber dade (TEO3, 1.06), Meu Senhor Muito estimo se estas enfeliz Li- 
nhas vai a char Vossa Excellencia gozando uma perfeita saúde e atodos quantos lhe pertencer (VIT, 1.02-04), Será satisfação para sêo escravo se estas linhas o encontrar com perfeita saude. (ARN, 1.03-04).

- Mim em lugar de eu: falla com elle para mim Saber (CLA3, 1.14-15).

- Clítico em posição inicial absoluta de uma oração: mi falta 198 mireis para minha li ber dade (TEO3, 1.06), mi fa ça o es te fa vor (CLA2, 1.09).

- Uso inadequado do clítico: Muito addemirava me naõ receiar-se com o meo genio (TIM, l.12-13), Naõ persuadaõ-se que eu fiz digo: que cometi este attentado, por temer o que estava-se fazendo... (TIM, 1.22-24).

- Dupla negação: quando Vossa Excellencia Cazoci com minha Senhor Maria eu não estava mesmo em Caza não (VIT, 1.23-25).

- Uso do você: Muto heide estimar que esta va a char vocé esteije com saude que meu dezeijo você me mande contar para honde voçé esta morando. (TEO1, 1.0105), ...eu fis uma pormeça em comgo voçé nao esta lembrado da pormeca que voçé que eu fis voçé não esta lembrado que voçé pai vedeu vo çé para voçé se lembra da pormeça... (TEO1, 1.08-13), eu heidi pricura por vose man dou mun to lem braça para vose... (TEO2, 1.06).

- Ele acusativo: ...e poriço voçé veija que arainha e maior do mundo e esta persa no mal não pode se salvar porque São Bendicto perdeu ella no mar (TEO1, 1.19-23).

- Queda do se pronominal: quem me arematou foi um moçó muito rico de campinas o homem chama Marciano quina... (TEO1, 1.05-08).

- Uso de 2 conjunções condicionais: ...me mande a reposta e dinhero va juntando la mesmo se czo eu maranjar por aqui mando propio la (TEO2, 1.11-15).

- Uso de della ao invés de sua: A Jaia Pombinha e a toda familia d'ella sou muito grato... (TIM, 1.06).

\section{Bibliografia}

ABAURRE, M. B. M. (1991) A relevância dos critérios prosódicos e semânticos na elaboração de hipóteses sobre segmentação na escrita inicial. Boletim da Associação Brasileira de Lingüística, 11, p. 203-217.

(2001) Dados iniciais da escrita infantil: indícios de construção da hierarquia de constituintes silábicos? In: HERNANDORENA, C. L. M. (org.). Aquisição de língua materna e de lingua estrangeira: aspectos fonéticos-fonológicos. Pelotas: EDUCAT/ALAB. p. 63-85.

ALKMIM, T. M. (2001) A variedade lingüística de negros e escravos: um tópico da história social do português no Brasil. In: MATTOS E SILVA, R. V. (org.) Para a bistória do português brasileiro. v. II: primeiros estudos. São Paulo: Humanitas, t. 2, p. 317-335.

. (2002) Estereótipos lingüísticos: negros em charges do séc. XIX. In: ALKMIM, T. M. (org.) Para a bistória do português brasileiro. v. III: novos estudos. São Paulo: Humanitas, p. 383-402.

BLANCHE-BENVENISTE, C. (1998) Estudios linguísticos sobre la relación entre oralidad y escritura. Barcelona: Gedisa. 
CÂMARA Jr., J. M. (2004) Dicionário de linguística e gramática. 25. ed. Petrópolis: Vozes. CAGLIARI, L. C. (1998) Alfabetizando sem o bá-bé-bi-bó-bu. São Paulo: Scipione. FAUSTO, B. (1994) História do Brasil. São Paulo: EDUSP/FDE.

FRASCADORE, A. (1991) Livelli di alfabetizzazione e cultura grafica a Lecce intorno alla metà del XVII secolo (1640-1659). In: LANGELI, B. A.; TOSCANI, X. (orgs.). Istružione, alfabetismo, scrittura. Saggi di storia dell'alfabetirzarione in Italia (sec. XV-XIX). Milano: Franco Angeli. p. 109-148.

KLEIMAN, A. (2001) O processo de aculturação pela escrita: ensino da forma ou aprendizagem da função? In: KLEIMAN, A.; SIGNORINI (orgs.) O ensino e a formação do professor: alfabetização de jovens e adultos. 2. ed. Porto Alegre: Artes Médicas. p. 223-243.

MARQUILHAS, R. (2000) A faculdade das letras. Leitura e escrita em Portugal no séc. XVII. Lisboa: Imprensa Nacional/Casa da Moeda.

MATTOS E SILVA, R. V. (2002) Para a história do português culto e popular brasileiro: sugestões para uma pauta de pesquisa. In: ALKMIM, T. M. (org.) Para a história do português brasileiro. v. III: novos estudos. São Paulo: Humanitas. p. 443-464.

MATTOSO, K. de Q. (2001) Ser escravo no Brasil. São Paulo: Brasiliense. [1982].

SILVA NETO, S. da (1950) Introducão ao estudo da lingua portuguesa no Brasil. 5. ed. Rio de Janeiro: Presença.

OLIVEIRA, K. (2004) E agora, com a escrita, os escravos! In: COSTA, S. B. B.; MACHADO FILHO, A. V. L. (orgs.) Do português arcaico ao português brasileiro. Salvador: EDUFBA. p. 139162.

(2005a) Y ahora, los esclavos brasileños y la escritura. In: GÓMEZ, A. C.; BLAS, V. S. (orgs.) Letras bajo sospecha. Gijón: Treas. p. 289-320.

. (2005b) O lugar do branco na escrita de negros. Notas sobre segmentação gráfica em textos de africanos e afro-descendentes no Brasil do século XIX. Revista Internacional de Lingua Portuguesa, 6, p. 153-170.

(2006) Negros e escrita no Brasil do século XIX: sócio-história, edição semidiplomática de documentos e estudo lingüístico. Salvador. Tese (Doutorado) •Universidade Federal da Bahia.

PETRUCCI, A. (1978) Scrittura, alfabetismo ed educazione grafica nella Roma del primo cinquecento. Da um libretto di conti di Maddalena Pizzicarola in Trastevere. Scrittura e Civiltà, 3, p. 163-207.

PICOLI, F. (2001) 'Para mio a mudasa na tie probemas': as primeiras produções escritas do alfabetizando adulto. In: KLEIMAM, A.; SIGNORINI, I. (orgs.) O ensino e a formação do professor: alfabetização de jovens e adultos. 2. ed. Porto Alegre: Artmed. p. 103-122.

SILVA, A. da (1994). Alfabetização: a escrita espontânea. São Paulo: Contexto.

SIMÕES, D. (2003) Fonologia em nova chave: considerações sobre a fala e a escrita. Rio de Janeiro: H. P. Comunicação.

ZORZI, J. L. (1998) Aprender a escrever: a apropriação do sistema ortográfico. Porto Alegre: Artmed.

ABSTRACT: The event that leads to the existence of this paper was the finding of thirteen texts written by slaves in XIX century Brazil. Those are rare documents because they appear to be, according to frequent historical studies, written by individuals that, for historical-social 
circumstances, didn't have access to litteracy. Such documents were edited according to semidiplomatic criteria, striving to maintain, as much as possible, their original caracteristics. The paper then analyzes above all, phenomena linked to the acquisition of the written language, such as graphic and graphic-phonic phenomena.

KEYWORDS: Brazilian Portuguese; text by slaves; $19^{\text {th }}$ century; linguistic analysis.

\section{Critérios de Edição}

1 A transcrição será conservadora.

2 As abreviaturas:

- Serão desenvolvidas as abreviaturas alfabéticas, marcando-se, em itálico, as letras omitidas.

- No caso de variação no próprio manuscrito ou em coetâneos, a opção será pela forma atual ou mais próxima da atual.

- Não serão desenvolvidas abreviaturas como $\int$ (parágrafo) e outras representadas por símbolos que, ainda hoje, têm o mesmo significado dos utilizados nos documentos.

3 Não haverá intervenção na marcação das fronteiras de palavras.

4 A pontuação original será rigorosamente mantida.

5 Os acentos gráficos e os diacríticos, usados pelos autores dos documentos, serão mantidos como no original.

6 Será respeitado o emprego de maiúsculas e minúsculas como se apresentam no original.

7 Reproduzir-se-ão os espaços intervalares deixados pelos autores.

8 Inserções dos autores nas entrelinhas serão indicadas na edição entre os sinais $<>$.

9 Supressões feitas pelos autores serão tachadas.

10 As linhas serão numeradas de 5 em 5 , à margem esquerda.

11 As intervenções feitas pelo editor - as conjecturas - virão entre os sinais [].

12 Se por deterioração material ou por difícil leitura, não se conseguir ler grafemas, vocábulos ou trechos, a indicação será feita da seguinte forma:

- $[$.$] - para grafemas$

- [?] - para vocábulos

- [??] - para trechos

13 Serão mantidas a mudança de linha e a disposição gráfica dos parágrafos.

14 A mudança de página, a partir da segunda, será sinalizada da seguinte maneira: [p2], [p3], etc. 
ARN - Carta escrita pelo escravo Arnaldo Rigão, na cidade do Rio de Janeiro, em 1862

Mêo Senhor Antônio Coelho

Rio 6 de Abril de 1862

Será satisfação para sêo escravo se

estas linhas o encontrar com perfeita saude.

05 Mêo Senhor pelo amor de vossos filhos the vou rogar que pela bondade de mêo Senhor tenha paciência com o sêo escravo Arnaldo pois mêo Senhor bem sabe a maneira que fui criado e hoje me vejo chicoteado todos os momentos não por

10 faltas de minha parte pois quando ando em mandado não ando corro e assim mesmo não satisfaco aos mêos senhores; por isso peco a mêo senhor que tenha paciencia em mandar procurar minha mai para pedir-lhe o dinheiro que ella tenha que

15 eu cá arranjo o resto, e espero em Dêos ainda hir ahi para agradecer o bem que mêo senhor me faca, e peco mais pela a bencão de Senhora mai de mêo Senhor não s esqueça de

Sêo Escravo muito Respeito Arnaldo Rigão

TIM - Carta escrita pelo escravo Timóteo, na cidade de Salvador, em 1861

Perdaõ

A muito tempo que tenho dezejo de não existir pois a vida me hé abborrecida porem naõ existindo naõ será mais pois quem pode

05 viver sem ter disgostos que vá vivendo A Jaia Pombinha e a toda familia d'ella sou muito grato por isto pesso pelo amor de deus Perdão sendo que com esta vez hé a $3^{a}$. que eu tenho tentado contra minha existencia

10 porem quem naõ quer viver nem deve tomar vidro, e nem sollimão pois só saõ lentos a quem tem a mor a vida. Muito addemirava me naõ receiar-se com o meo genio [em] não fazer um acerto para mim pois naõ acho 15 doudice n'este proceder. 
p2

Naõ há tempo [a] perder!!!!

Poz-me preciso declarar-me que nem foi eu, e nem sabedor daquelle infaime papel, e n'elle achava-me inocente. Se faço esta declaraçaõ é

20 para livrar que vaõ ao Inferno, estas almas que despistaraõ suas conciencias!.....

Naõ persuadaõ-se que eu fiz digo: que cometi este attentado, por temer o que esta va-se fazendo; pois para passar melhor, não

25 havia que temêr: as rasões saõ outras pois a sepultura será sabedôra, e naõ este infaime lugar digo e naõ esta terra de vivos

VIT - Carta escrita pelo escravo Vitorino, na cidade de Cachoeira/BA, em 1879

Illustríssimo Excelentíssimo Senhor Antonio De Aragão Bucão

Meu Senhor Muito estimo se estas enfeliz Linhas vai a char Vossa Excellencia gozando uma perfeita saude e atodos quantos lhe pertencer, pois é o que

05 este seo Escravo obidiente pode dezejar Vossa Exce llencia, meu Senhor Venho por meio destas enfeliz linhas prostarme em Vossos honrado pés pedindo a Vossa Excellencia pelo o amor que Vossa Excellencia tem a minha Senhor Maria

10 fazer com que eu Vá comprir aminha $\mathrm{p}$ pena na Cidade de Cachoeira que tem minha Mai que móra Lá mesmo, para mim sempre é melhor, eu estar no meio dos meus embora eu pagei a sesta parte, porém sou

15 mais satisfeito estar no meio dos meus e é quem pode ter compaichão de mem é o meu Senhor mesmo abaicho de Deus, por reconhecer que é quem pode ter pena de mim sendo o Seu Escravo, pois tendo omeno aproteição dos

20 Carçado de minha Senhor Maria Sou a ttendido pur tanto é com quem eu me apego. Vossa Excellencia não tem comhecimento com migo pur que quando Vossa Excellencia Cazoci com minha Senhor Maria eu não estava mesmo em

25 Caza não. estava retirado no Ingenho da Carai ba, e com deferencia de 8 dias pouco mas 
214 OLIVEIRA, Klebson. Textos de escravos no Brasil oitocentista: os tempos de uma edição filológica...

ou menos me a conteceu o fato que é urige

da minha enfelicidade, foi a razão de Vossa Excellen

cia [?] este seu Escravo e não Conhecer, por

30 tanto espero pelo amor da minha Senhor [?] ser

[p2]

attindido que Deus é quem Vos para mim pagará com

muitos Annos de Vida e omento entoda Vossa

Excelentíssima Família,

De Vossa Exellencia Escravo obediente Vitorino

35 Bahia Caza da Prizão

Comtrabalho

20 de julho de 1879

CLA1 - Procuração escrita pelo escravo Claro Antônio dos Santos, na cidade de São Paulo, em 1867

em Sao Paulo no dia 21 de fer verio de $18 \partial 7$

Illustríssimo Senhor

1 mais cor lete de es da peta com huma gavata $9 \$ 000$

1 hum di to Cha peo de Sol de es da

$8 \$ 000$

051 mais hum Cha peo de car be ça

1 hun di to Cha le de lam bam Co

$7 \$ 000$

1 mais di ta caixa de es da peta

$9 \$ 000$

1 di ta hum a i car ça de gar re nira peta

$12 \$ 000$

1 di to hum i car ça de bin Co

101 di to hum pa li to de lam

$\hat{o} \$ 000$

1 di to hu camiza de lam vermeia

$\$ 4$ ca miza de a mor ri fim mo

2 ca mi za de xita

$33 \$ 000$

1 di to mais huma pe da de com es va

$1 \$ 000$

151 mais hum di to i to jo de na vaia mais hum Cha peo de cabeça

pa ço eta pecura caõ para Semhor Framcis $<$ co $>$

Be me dito de a Sil pela or dem mimha

Claro Amtonio do Santos 
CLA2 - Carta escrita pelo escravo Claro Antônio dos Santos, na cidade de São Paulo, em 1867

São Paulo 1 de Maço de $18 \partial 7$

Illustríssima Senhora Dona Je tu de de

Jeus Maria da Comceiçaõ noto

bem para Vossa mercê fil ca Saben do que eu paso a min<há>

05 or dem para Senhor meu ami go Francisco

Be ne dito de a Sis a quantia de Sem mi reis

com to do pur isso no fim do anno tem elle de

a re ce ber a di quantia tem a minha Senhora te

ta mi fa ça o es te fa vor no mais Sou de de Vossa mercê

10 esi Cravo Cri a do o bri gado

Claro Antonio do Santos

Seu Si to

Jui qui ri

CLA3 - Carta escrita pelo escravo Claro Antônio dos Santos, na cidade de

São Paulo, em 1867

Illustríssimo Senhor J no cem so de memto

Sao Paulo $1^{\circ}$ de Ma ço de $18 \partial 7$

eu es tima e ri que eta dua linha que

$05 \mathrm{~V}$ a a Cha o meu es ti ma do Senhor

com muita Sau de como para mim

dezeio noto bem para Vossa Mercê fil Ca

Sa bem do que eu ia fai É es mom

na que eu ando fora de mimha

10 caza eu ia Cuber que o Senhor

vai para o Ju diahi vemho falla

com Senhor Fr ancisco Be ne dito de Asil

na Rua de Santa Curlze pe ga do

o pos tao de minha caza falla com

15 elle para mim Saber no mais

Sou de Vossa Mercê es i cravo criado O

Birgado Claro Antonio <do $>$ Santos

p2

Illustríssimo Senhor I no cemCo 
216 OLIVEIRA, Klebson. Textos de escravos no Brasil oitocentista: os tempos de uma edição filológica...

de mento e Sua

20 fal zem da Vajes de Santo

Mar rio

TEO1 - Carta escrita a pedido da escrava Teodora, na cidade de São Paulo, década de 60 do século XIX

Meu Marido Senhor Luis

Muto heide estimar que esta va a char vocé esteije com saude que meu de zeijo você me mande contar para

05 honde voçé esta morando. Quem me arematou foi um moçó muito rico de campinas o homem chama Marciano quina eu fis uma pormeça em comgo voçé nao esta

10 lembrado da pormeca que você que eu fis voçé não esta lembra do que voçé pai vedeu vo CE para voçé se lembra da porme ça que me a visou de noite eu

15 estava dormindo Rainha tem companheiro de fazer pormeça e não compir e agora ella esta persa no Imal. e poriço façilli tal com santos e poriço você

20 veija que arainha e maior do um ndo e esta persa no mal não pode se salvar porque São Bendic to perdeu ella no mar não pode se calvar e poriço eu não façi

25 lito com santos eu espero hin da compir ainda que esteja com cabelos braços sua senhor dice que desfacado de dar carta de forria de ajuntar o carsar responcado

30 tambem de ajuntar casar ganhou dinheiro pagar o Seu Senhor da carta de arfuria eu quero ocasar junto e

p2 para não ganhar dinheiro e dispois em tão ganhar dinheiro pagar 
35 primeiro pagar a minha pormeça

dispos para pagar sua senhoria

senão fica como a rainha

TEO2 - Carta escrita a pedido da escrava Teodora, na cidade de São Paulo, década de 60 do século XIX

Meu marido Luis

São Paulo

Mumito ide istimar que Vossa Mercê iste

ja Com Saude eu is tou aqui naci

05 dade eu vos is Crevo para Vossa Mercê selem

bra daquela promeça que nois fi

zemos eu heidi pricura por vose

man dou mun to lem braça para

vose e ajun ta hum dinhero

10 la sepuder [?] vimfalar com mi

go venha senão puder me $\mathrm{m}$

ande a reposta e dinhero va

juntando la mesmo se czo

eu maranjar por aqui man

15 do propio la

Dessa vosça Mulher

Theodoria escrava do connio

terra que fui vin dida

na vacaria

$\mathrm{p} 2$

20 Illustríssimo Senhor Luis is Cravo dodefuto Joaõ rodrigo da Cunha

Cidade da Limera

TEO3 - Carta escrita a pedido da escrava Teodora, na cidade de São Paulo, em 1866

Illustríssimo Senhor Luiz da Cunha em

São Paulo 20 de otu... de $18 \partial \partial \partial$

Eu es de tima muito qeu e ta que vom gorzamdo

e a sua filicidade como para mim dezeio noto bem para

05 mi fazer o fa vou de vi por o nata falla com migo 
218 OLIVEIRA, Klebson. Textos de escravos no Brasil oitocentista: os tempos de uma edição filológica...

sem falta mi falta 198 mireis para minha li ber dade no mais mi mamde a repota des ta para o senhor de mi cian no na ci da de de solr cra va sen falta no mais eu i tou pagamdo

10 como huma i crava deste pader ma vado no mais a Deus a Deus a te hum dia que Deus no a jun de com sua garça devima mizeicode no mais sou a sua mulhe

Ti a do ra da Cunha dia p2

15 Illustríssimo Senhor Luiz dia da cunha cera $i$ tegue para o i cravo do senhor João dia da cunha na ci da de da lin nera

TEO4 - Carta escrita a pedido da escrava Teodora, na cidade de São Paulo, década de 60 do século XIX

Illustríssimo Senhor i nos senÇo

e m São Paulo 20 de <novembor [?]>

05 Meo filho eu es de ti ma muito e a sua sau de conno para mim dezeio noto bem pa vo es mi mandra comta como vai de sau de nos mais eu bos to a mimha bremcao Deos te a be so para muito tempo ti de sau

10 de como para nim deze no to bem para sou a tua maiti a dora no mais a Deos

p2 Illustrímo Senhor no cemso

15 hum a falzemda de par to [?] Luize Bira<po>ra Ju di a hi 
TEO5 - Carta escrita a pedido da escrava Teodora, na cidade de São Paulo, em 1866

Meu mari do Luis

São Paulo 21 de A gos to de $18 \partial \partial$

Mumito eu esti ma a sua saude como para mim dezeio noto bem para [?] mi faça o

05 favor de mi ajum ta a gu $m$ dimhe ro para mim eu já tem ho É4 mireis no mais pase muito bem eu tou na ci da de de São Paulo na caza do Senhor comgo terra

Te a do Ra

TEO6 - Carta escrita a pedido da escrava Teodora, na cidade de São Paulo, em 1866

Illustríssimo Senhor de mi cian no dia da

Cunha

18 "

em São Paulo É0 de o tu de

eu i de ti ma que eta va a Cha o a

05 Vossa Senhoria com muita fili cida de

com para $<$ mim $>$ dezeio no to bem

para Vossa Senhoria mi faca o fa vo $<\mathrm{r}>\mathrm{de}$

mi mam da eta crata para

ci da de da lin nera pa ra meu

10 ma ri do Luiz da cunha

Ti a do ra da cun ha

p2

Illustríssimo Senhor de mi ciano

dia da Cunha para cidade

de Sol lu ca va

TEO7 - Carta escrita a pedido da escrava Teodora, na cidade de São Paulo, década de 60 do século XIX

\section{Meu Senhor}

Eu tive hum avizo de noute vinha-me e me falava dizendo que comprice apro meça que promiti devortar para minha

05 terra esta conga que fala comigo dis 
220 OLIVEIRA, Klebson. Textos de escravos no Brasil oitocentista: os tempos de uma edição filológica...

que ceu [meredo] a qui não compraei

por meça que nem eu enxú Vossa Mercê d'e<sta>

prome Ca por meu pai foi cum

pado deu servidia po $<$ r $>$ que deos não que $<$ r $>$

10 que se a parte caza de preto $\mathrm{de}<\mathrm{A}>$ gola meu

Sinhor Vossa Mercê e reponsado de ajum

$\operatorname{tar}$ Cen eu isto querede meforca que

ro Vossa Mercê de lisensa para eu tira esmola

nos domingo para hi dando para Sinhor eu

15 ja tenho 4 milreis e Vossa Mercê ja ten 9 milreis

na sua maõ

is Crava de Vossa Mercê

Ti o do ria 